\title{
Efficacy and side effects of praziquantel against Schistosoma mansoni in a community of western Côte d'Ivoire
}

\author{
Giovanna Raso $^{\mathrm{a}, \mathrm{b}}$, Eliézer K. N'Goran ${ }^{\mathrm{b}, \mathrm{c}}$, Abale Toty ${ }^{\mathrm{d}}$, \\ Anne Luginbiuhl ${ }^{b, e}$, Cynthia A. Adjoua ${ }^{b, f}$, Norbert T. Tian-Bi ${ }^{c}$, \\ Isaac I. Bogoch ${ }^{b, g}$, Penelope Vounatsou ${ }^{a}$, Marcel Tanner ${ }^{a}$, \\ Jürg Utzinger ${ }^{\mathrm{h}, *}$
}

a Swiss Tropical Institute, P.O. Box, CH-4002 Basel, Switzerland
b Centre Suisse de Recherches Scientifiques, 01 BP 1303, Abidjan 01, Côte d'Ivoire
c UFR Biosciences, Université de Cocody, 22 PB 770, Abidjan 22, Côte d'Ivoire
d Direction Départementale de la Santé de Man, Man, Côte d'Ivoire
e Institute for Infectious Diseases, University of Bern, CH-3010 Bern, Switzerland
f Département de Sociologie, Université de Cocody, Abidjan, Côte d'Ivoire
g Faculty of Medicine, University of Toronto, Toronto, M5S 1A8, Canada
h Office of Population Research, Princeton University, Princeton, NJ 08544, USA

Received 28 April 2003; received in revised form 12 June 2003; accepted 23 June 2003

KEYWORDS
Schistosomiasis;
Schistosoma mansoni;
Praziquantel;
Efficacy;
Side effects;
Kato-Katz thick smear;
Côte d'Ivoire

Cote d'voire

\begin{abstract}
Summary Praziquantel is efficacious against the adult stages of all human schistosome parasites, and has become the drug of choice for morbidity control of schistosomiasis. There is concern that resistance to praziquantel might develop or already exists, and could be further facilitated through new control initiatives relying on large-scale administration of praziquantel. Therefore, monitoring praziquantel efficacy in different epidemiological settings is required. We assessed the efficacy and side effects of praziquantel against Schistosoma mansoni in a rural community of western Côte d'Ivoire. Three consecutive stool specimens from 545 children and adults were examined by the Kato-Katz technique, revealing an overall prevalence of $40.9 \%$. S. mansoni-infected individuals were treated with a single oral dose of praziquantel at $40 \mathrm{mg} / \mathrm{kg}$. The most frequent side effects were abdominal pain, dizziness and diarrhoea. The overall cure rate, assessed 6 weeks post-treatment, was $60.9 \%$. Moderate or heavy infections were only cleared in half or one-third of the individuals, respectively. The total egg count reduction was $61.4 \%$. Infection intensity pre-treatment was significantly associated with age, cure rate, reported diarrhoea and dizziness. Our findings call for additional studies that rigorously evaluate the efficacy of praziquantel against different schistosome species in entire communities, using similarly sensitive diagnostic approaches as employed here.

(c) 2003 Royal Society of Tropical Medicine and Hygiene. Published by Elsevier Ltd. All rights reserved.
\end{abstract}




\section{Introduction}

Praziquantel is the current drug of choice for the treatment and morbidity control of schistosomiasis. Its efficacy against all five species of human schistosomes, good tolerability, ease of administration, and substantial price reduction (average cost for adult treatment in 2003 is US\$ 0.30 ) are key features explaining the success of this drug (Bergquist, 2002; Doenhoff et al., 2002; Fenwick et al., 2003). Using the recommended dosages, cure rates recorded in a 1984 review were: 75$85 \%$ for Schistosoma haematobium, $63-85 \%$ for S. mansoni, and $60-80 \%$ for mixed infections with S. mansoni and S. haematobium (Wegner, 1984). More recent studies found cure rates of $60-90 \%$ for S. mansoni in different epidemiological settings (Davis, 1993; Gryseels et al., 1987; Kumar and Gryseels, 1994; Utzinger et al., 2000a). However, in an intensive focus in northern Senegal, the drug resulted in very low cure rates, namely $18-39 \%$ (for recent reviews see Danso-Appiah and De Vlas, 2002; Gryseels et al., 2001). Side effects due to praziquantel usually occur in a relatively large proportion of patients (30-60\%), but they are mild and transient and disappear within $24 \mathrm{~h}$ (Berhe et al., 1999; Cioli and Pica-Mattoccia, 2003; Jaoko et al., 1996; N'Goran et al., 2003).

The major weaknesses of praziquantel are its lack of efficacy against immature parasites (Sabah et al., 1986; Xiao et al., 1985), and the risk of resistance development (Danso-Appiah and De Vlas, 2002). The stage-specific efficacy of praziquantel is thought to be the likely source of most treatment 'failures' experienced in clinical practice (Cioli and Pica-Mattoccia, 2003). In areas of intense transmission people are likely to be infected simultaneously with different developmental stages of the parasite. Two praziquantel treatments, given a few weeks apart, showed promising results with elevated cure rates and egg count reductions (N'Goran et al., 2003; Picquet et al., 1998; Renganathan and Cioli, 1998; Utzinger et al., 2000a). Another potentially interesting approach is combination chemotherapy with praziquantel and an artemisinin derivative, because these compounds are complementary with regard to their stage-specific susceptibilities (Utzinger et al., 2003).

According to the overall endemicity of schistosomiasis in a given setting, WHO currently recommends either selected treatment of infected individuals or systematic praziquantel administration (WHO, 2002). However, the prospect of relying on a single drug for a disease affecting 200 million people is an alarming situation
(Cioli, 2000). In addition, it is anticipated that praziquantel usage will increase with the recent launch of the 'Schistosomiasis Control Initiative' (http://www.schisto.org), and the deworming and school-feeding programmes of the World Food Programme, the World Bank and WHO, already operating in 19 of the 41 endemic African countries (Fenwick et al., 2003; Savioli et al., 2002). Consequently, monitoring the efficacy of praziquantel in different epidemiological settings is a high priority (Renganathan and Cioli, 1998) and has to be built into operational programmes (WHO, 1999).

Recently, an attempt to interpret low S. mansoni cure rates from Senegal on the basis of trends from other studies was carried forward (Danso-Appiah and De Vlas, 2002). The authors identified 11 studies that met the following inclusion criteria: (1) studies involved entire communities or representative sub-samples thereof; (2) participants received a single oral dose of $40 \mathrm{mg} / \mathrm{kg}$ praziquantel; (3) treatment outcomes were expressed as a cure rate; and (4) praziquantel efficacy was assessed between 1 and 12 months post-treatment. The authors concluded that even if high pre-treatment intensities of infection could partly explain low cure rates, the suspicion about tolerance or resistance to praziquantel could not be ruled out for Senegal. The limited number of studies and the fact that they all employed slightly different designs and diagnostic procedures, call for additional studies in other settings.

This paper reports the first evaluation of the efficacy and side effects of praziquantel against S. mansoni in an entire community of Côte d'Ivoire. A sensitive diagnostic approach was employed by quantitative examination of 3 consecutive stool specimens per individual prior and after praziquantel administration. The study estimates cure rates and egg count reductions, and assesses side effects after treatment, placing special emphasis on associations to pre-treatment infection intensities.

\section{Materials and methods}

\subsection{Study area, population and consent}

The study was carried out in Zouatta II, a village situated in the district of Man in western Côte d'Ivoire. This area has been reported to be a major focus of S. mansoni several decades ago (Service des Grandes Endémies, 1970; cited in Doumenge et al., 1987). This has been confirmed by a recent, 
large-scale, cross-sectional survey, when examination of $>5000$ schoolchildren revealed an infection prevalence of S. mansoni of 54\% (Utzinger et al., 2000b).

The study was launched in May 2002. First, the village chief was asked for permission to work in Zouatta II, and then a meeting was organized with the village authorities to explain the aims and procedures of the study. After consent was obtained and the village chief had designated 8 persons to assist our research team, the village authorities informed the community. A detailed demographic survey was carried out in 75 households, randomly selected among the estimated 100-120 households, according to the EPI survey approach (Lemeshow and Robinson, 1985). For each household, the number of inhabitants was recorded and the geographic coordinates were collected using a hand-held GPS (Magellan 320). For each individual, the name, sex and age were recorded. Identification numbers were then assigned to each household, as well as each participant. Two researchers specialized in the fields of sociology (C.A. Adjoua) and socio-geography and visual communication (A. Luginbühl), together with the 8 local assistants, conducted a questionnaire survey, both at the household and the individual level. Pre-tested questionnaires were utilized for appraisal of socio-economic factors, perceived morbidity indicators and health-seeking behaviour patterns.

Subsequently, a detailed parasitological survey was carried out. Due to logistic reasons and the capacity of our laboratory technicians to process a maximum of 300 stool and 300 urine specimens per day, the selected households were geographically split into 2 similarly large groups. In the evening before the first parasitological survey commenced, the study participants reassembled at the village chief's domicile and the procedures of the forthcoming survey and subsequent treatments were explained.

\subsection{Field and laboratory procedures}

The 8 people assisting our research team went from one household to another and distributed pre-packed plastic bags containing stool and urine containers, marked with the name and identification number of each participant in group 1 . The household chiefs were asked to return the containers early in the next morning, filled with small amounts of fresh stool and urine specimens, to a central location in the village. In cases where the household head was unable to return the filled containers, another member of the same household could fulfil this task. This procedure was repeated over 3 consecutive days. It allowed study participants to go to work in the fields or attend school during survey days. On the third day, all study participants of group 1 were also invited for a full clinical examination and to provide finger prick blood samples for thick and thin blood films. Thereafter, treatment against $S$. mansoni and soil-transmitted helminths or other ailments, was administered. Group 2 was enrolled from day 5 onwards, adhering to the same field procedures. These activities were completed on day 7 by a full clinical examination, investigation of malaria parasites, and subsequent drug administration.

Stool, urine and blood specimens were brought to the central laboratory in Man. The stool specimens were processed as follows. First, a $1-2 \mathrm{~g}$ portion of each specimen was preserved in $10 \mathrm{ml}$ sodium acetate-acetic acid-formalin (SAF). Second, a single Kato-Katz thick smear was prepared from each specimen, using $42 \mathrm{mg}$ plastic templates (Katz et al., 1972). After a clearing time of 30$45 \mathrm{~min}$, the Kato-Katz thick smears were examined by light microscopy, and eggs of S. mansoni, hookworms, Ascaris lumbricoides and Trichuris trichiura were recorded by 4 experienced microscopists. For quality control, $10 \%$ of the slides were randomly selected at the end of each day and re-examined by the senior microscopist.

The SAF-conserved stool samples were forwarded to a reference laboratory in Switzerland for appraisal of intestinal protozoa. Urine specimens were tested with reagent strips (Nephur 6-Test ${ }^{\circledR}$, Roche Diagnostics, Mannheim, Germany), and 3-4 $\mathrm{ml}$ of urine were frozen and forwarded to a reference laboratory in the UK for NMR-based metabonomic analyses. Thick and thin blood films were stained with Giemsa and species-specific densities of Plasmodia were estimated under a microscope, following standardized, quality-controlled procedures. These results will be presented elsewhere.

\subsection{Chemotherapy, reported side effects and follow-up}

After the last stool specimens had been obtained from study participants in group 1 (day 3 ) and group 2 (day 7), all individuals who had resulted positive for $S$. mansoni were invited for praziquantel treatment at a single oral dose of $40 \mathrm{mg} / \mathrm{kg}$. Individuals who were S. mansoni-negative but had an infection with soil-transmitted helminths (hookworms, A. lumbricoides or T. trichiura) were treated with albendazole $(400 \mathrm{mg})$. Adults who were infected neither with S. mansoni nor any soil-transmitted 
helminth received vitamins. When the full clinical examination by the study physician revealed other diseases/conditions, the patients were referred for treatment to the central laboratory in the town of Man.

Individuals treated with praziquantel were instructed to report side effects within $24 \mathrm{~h}$ post-treatment. The list of symptoms included nausea, vomiting, abdominal pain, diarrhoea, itching, headache, urticaria and dizziness. Six weeks later a follow-up survey was carried out among these individuals. Stool specimens were again collected over 3 consecutive days and Kato-Katz thick smears were quantitatively examined. Individuals who continued to excrete $S$. mansoni eggs in their faeces were treated with another dose of praziquantel, also administered at $40 \mathrm{mg} / \mathrm{kg}$.

\subsection{Data management and statistical analyses}

Data were double entered and cross-checked using Epilnfo (version 6.04, Centers for Disease Control and Prevention, Atlanta, GA, USA). Analyses were performed with STATA (version 7.0, Stata Corporation, College Station, TX, USA). Praziquantel efficacy was calculated for those study participants who had at least 2 Kato-Katz thick smears examined pre- and post-treatment and were administered praziquantel. To estimate the mean S. mansoni egg counts of each individual, the arithmetic means were calculated both at the baseline and follow-up surveys. These arithmetic means determined the infection intensity of each individual and were utilized to calculate geometric means for the population. Infection intensities were subdivided into 3 categories as follows: (1) light infection: 1-100 eggs/g of stool (epg); (2) moderate infection: 101-400 epg; and (3) heavy infection: $>400$ epg (WHO, 2002). Age was subdivided into 5 categories: $<10$ years; $10-14$ years; $15-24$ years; $25-39$ years; and $\geq 40$ years. The parasitological cure rate was calculated as the proportion of individuals who had S. mansoni eggs in their stool prior to praziquantel administration and those who excreted no eggs after treatment. Egg count reduction was calculated as [1 - (geometric mean epg after treatment/geometric mean epg before treatment)] multiplied by a factor 100 . The groups were compared with the $\chi^{2}$-test, Fisher's exact test and Mann-Whitney statistics, including 95\% confidence intervals $(\mathrm{Cl})$ of means. Side effects were analysed by examining separately each one of the 8 specific side effects in relation to $S$. mansoni infection intensity.

\section{Results}

\subsection{Operational results and study compliance}

In May 2002, data pertaining to demographic, socio-economic, perceived morbidity indicators, infection risk- and health seeking behaviour patterns were collected from all inhabitants of 75 randomly selected households in Zouatta II. During the cross-sectional parasitological baseline survey, 561 individuals participated. The large majority, namely $545(97.1 \%)$, provided at least 2 stool specimens, hence they were considered for detailed analyses (Fig. 1). The numbers of male and female participants were similar (ratio $=1.04 ; \chi^{2}=0.49$, $P=0.70)$. Participants' ages ranged from 5 days to 91 years, consisting of: $<10$ years, $n=184(33.8 \%)$; 10-14 years, $n=74$ (13.6\%); $15-24$ years, $n=75$ (13.8\%); 25-39 years, $n=101$ (18.5\%); and $\geq 40$ years, $n=111(20.4 \%)$. Children aged $10-14$ years consisted of twice as many boys as girls ( 50 versus 24), whereas in older age categories there were slightly more women than men. This resulted in a

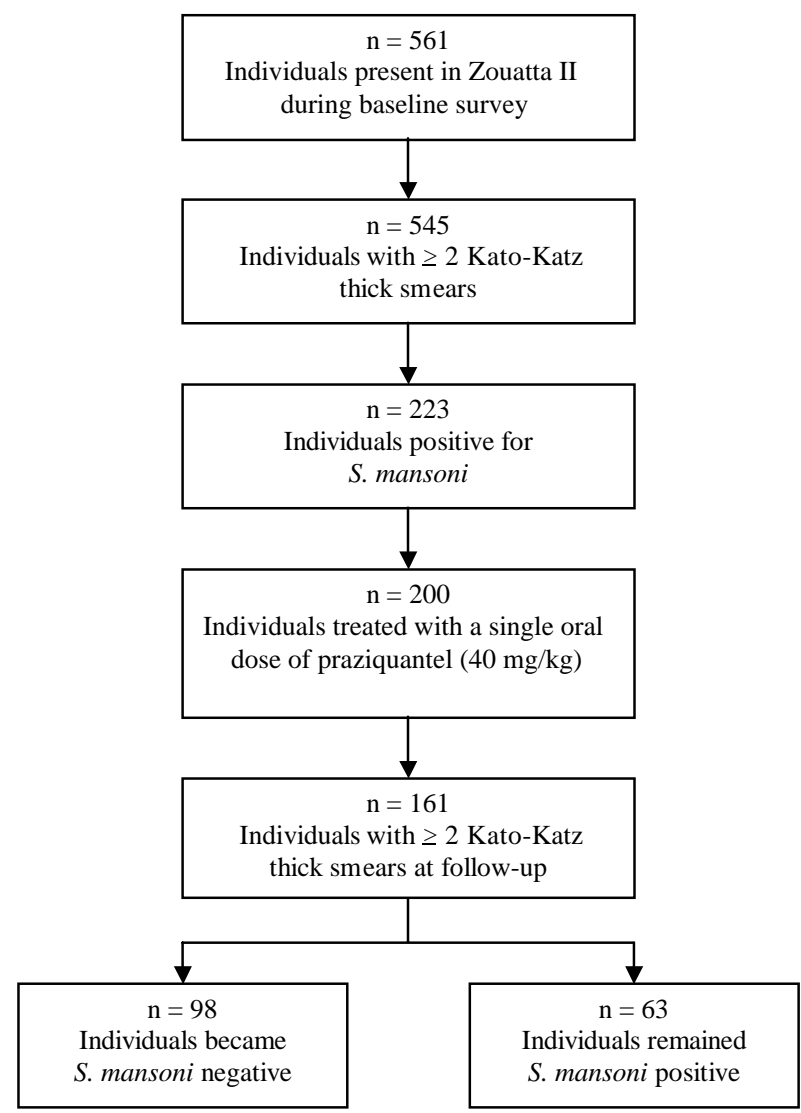

Fig. 1 Study compliance for assessment of efficacy and side effects of praziquantel against Schistosoma mansoni in the village of Zouatta II, western Côte d'Ivoire. 
Table 1 Number (\%) of study participants with Schistosoma mansoni infections at different intensity levels and geometric mean egg count for the population before the administration of praziquantel in the village of Zouatta II, western Côte d'Ivoire $(n=545)$

\begin{tabular}{llcr}
\hline S. mansoni infection level (eggs/gram stool) ${ }^{\mathrm{a}}$ & \multicolumn{2}{l}{ Cumulative results: no. of individuals (\%) } \\
\cline { 2 - 4 } & After sample 1 & After sample 2 & After sample $3^{\mathrm{b}}$ \\
\hline Light infection $(1-100)$ & $74(13.6)$ & $123(22.6)$ & $145(26.6)$ \\
Moderate infection $(101-400)$ & $36(6.6)$ & $49(9.0)$ & $57(10.4)$ \\
Heavy infection $(>400)$ & $27(4.9)$ & $25(4.6)$ & $21(3.9)$ \\
All infections $(>0)$ & $137(25.1)$ & $197(36.2)$ & $223(40.9)$ \\
Geometric mean egg count $(95 \% \mathrm{Cl})$ & $122(98-152)$ & $69(57-83)$ & $57(47-69)$ \\
\hline
\end{tabular}

${ }^{a}$ For stratification into different infection intensity levels, after collection of 2 or 3 samples, arithmetic means were used to establish the mean egg count of each individual.

b 98 of 545 individuals provided 2 instead of 3 stool specimens.

significant effect of the association between age categories and $\operatorname{sex}\left(\chi^{2}=9.88\right.$, d.f. $\left.=4, P=0.04\right)$. The mean age between the 2 sexes was not significantly different $($ men $=22.4$ years, women $=23.7$ years; Mann-Whitney $z=-0.81, P=0.42$ ).

\subsection{S. mansoni infection before praziquantel treatment}

Table 1 shows the prevalence, infection intensity and geometric mean egg counts of S. mansoni among the 545 study participants before the administration of praziquantel after sample 1 , sample 2 and sample 3. Examination of the first Kato-Katz thick smear revealed eggs of S. mansoni in 137 participants equal to an observed prevalence of $25.1 \%$. The prevalence of infection was as high as $40.9 \%$ after the examination of 3 consecutive Kato-Katz thick smears. A considerable number of patients displaying light infections, but to some degree also moderate infections, were missed by a single Kato-Katz thick smear. In contrast, heavy infections were all detected after the first stool examination. After the maximum sampling effort of 3 Kato-Katz thick smears, $26.6 \%$ of the study participants displayed light, $10.4 \%$ moderate and $3.9 \%$ heavy infections. The geometric mean egg count among all those individuals who were S. mansoni positive was 57 epg (95\% Cl: 47-69).

There was no significant association between level of infection intensity and $\operatorname{sex}\left(\chi^{2}=0.83\right.$, d.f. $=3, P=0.84$; Table 2 ). On the other hand, the association between level of infection intensity and age categories was highly significant with the age group of 15-24 years exhibiting the highest infection intensity $\left(\chi^{2}=119.29\right.$, d.f. $=12$, $P<0.001$; Fig. 2). Consequently, further analyses were performed for the 5 different age categories.

The observed prevalences of hookworm, $T$. trichiura and $A$. lumbricoides, following examination of 3 Kato-Katz thick smears, were $36.1 \%, 5.3 \%$ and $1.7 \%$, respectively.

Table 2 Baseline characteristics of Schistosoma mansoni infections among 545 study participants from the village of Zouatta II in western Côte d'Ivoire with regard to sex and age

\begin{tabular}{|c|c|c|c|c|c|c|}
\hline \multirow[t]{2}{*}{ Indicator } & \multicolumn{4}{|c|}{ Infection intensity } & \multirow[t]{2}{*}{$x^{2}$} & \multirow[t]{2}{*}{$P$-value } \\
\hline & None infected & Light & Moderate & Heavy & & \\
\hline \multicolumn{7}{|l|}{ Sex } \\
\hline Male & 160 & 75 & 31 & 12 & & \\
\hline Female & 162 & 70 & 26 & 9 & 0.83 & 0.84 \\
\hline \multicolumn{7}{|c|}{ Age (years) } \\
\hline$<10$ & 159 & 22 & 2 & 1 & & \\
\hline $10-14$ & 43 & 22 & 6 & 3 & & \\
\hline $15-24$ & 17 & 36 & 19 & 3 & & \\
\hline $25-39$ & 49 & 28 & 16 & 8 & & \\
\hline$\geq 40$ & 54 & 37 & 14 & 6 & 119.29 & $<0.001$ \\
\hline
\end{tabular}


Table 3 Number (\%) of study participants with Schistosoma mansoni infections at different intensity levels and geometric mean egg count for the population 6 weeks after praziquantel treatment (single oral dose of $40 \mathrm{mg} / \mathrm{kg}$ ) among 161 people

S. mansoni infection level (eggs/gram stool) ${ }^{a}$

Cumulative results: no. of individuals (\%)

\begin{tabular}{lccc} 
& After sample 1 & After sample 2 & After sample $3^{\text {b }}$ \\
\cline { 2 - 4 } Light infection $(1-100)$ & $13(8.1)$ & $35(21.7)$ & $56(34.8)$ \\
Moderate infection $(101-400)$ & $5(3.1)$ & $7(4.4)$ & $5(3.1)$ \\
Heavy infection $(>400)$ & $2(1.2)$ & $1(0.6)$ & $2(1.2)$ \\
All infections $(>0)$ & $20(12.4)$ & $43(26.7)$ & $63(39.1)$ \\
Geometric mean egg count $(95 \% \mathrm{Cl})$ & $64(37-112)$ & $33(23-48)$ & $22(16-30)$ \\
\hline
\end{tabular}

${ }^{a}$ For stratification into different infection intensity levels, after collection of 2 or 3 samples, arithmetic means were used to establish the mean egg count of each individual.

b 23 of 161 individuals provided 2 instead of 3 stool specimens.

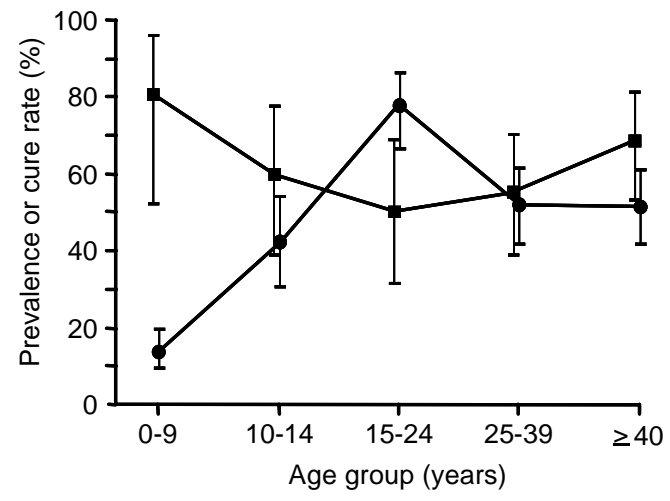

Fig. 2 Age-prevalence curve of Schistosoma mansoni

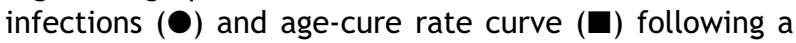
single oral dose of $40 \mathrm{mg} / \mathrm{kg}$ praziquantel (vertical bars indicate $95 \%$ confidence intervals).

\subsection{Effect of praziquantel and parasitological cure rate}

From those 223 participants found with S. mansoni eggs during the baseline survey, 200 (89.7\%) were treated with a single oral dose of $40 \mathrm{mg} / \mathrm{kg}$ praziquantel. The remaining 23 individuals missed treatment, because they were travelling, preferred to work or refused to take the drugs. Six weeks later, 161 participants provided at least 2 stool specimens, hence this cohort was utilized for estimation of the parasitological cure rate. Table 3 summarizes the prevalence, infection intensity and geometric mean egg counts among this cohort after examination of sample 1 , sample 2 and sample 3 . The observed prevalence after examination of the first Kato-Katz thick smear was $12.4 \%$. It increased 3 -fold, reaching an overall prevalence of $39.1 \%$ after 3 Kato-Katz thick smears had been examined. This translates to an overall cure rate of $60.9 \%$. Had only the first Kato-Katz thick smear been examined, the cure rate would result in $87.6 \%$, and hence would have been significantly overestimated. The geometric mean egg count among egg positive individuals was $22 \mathrm{epg}(95 \% \mathrm{Cl}: 16-30)$, resulting in a total egg count reduction of $61.4 \%$. There were still 7 individuals displaying either moderate or heavy infections. The overall cure rates among individuals who had light, moderate or heavy infections pre-treatment were $70.3 \%, 50.0 \%$ and $33.3 \%$, respectively (Table 4 ). Consequently, there was a significant association between cure rates and level of infection intensities prior to treatment $\left(\chi^{2}=11.58\right.$, d.f. $\left.=2, P=0.003\right)$, but cure

Table 4 Effect of single oral dose of $40 \mathrm{mg} / \mathrm{kg}$ praziquantel administered to $161 \mathrm{~S}$. mansoni-infected patients in Zouatta II, western Côte d'Ivoire in relation to infection intensity pre-treatment

\begin{tabular}{|c|c|c|c|c|c|c|}
\hline \multirow{2}{*}{$\begin{array}{l}\text { S. mansoni infection level } \\
\text { pre-treatment (eggs/gram } \\
\text { stool) }\end{array}$} & \multirow{2}{*}{$\begin{array}{l}\text { No. of } \\
\text { patients } \\
\text { treated }\end{array}$} & \multirow{2}{*}{$\begin{array}{l}\text { No. of } \\
\text { patients } \\
\text { cured (\%) }\end{array}$} & \multicolumn{4}{|c|}{ No. of patients non-cured } \\
\hline & & & $\begin{array}{l}\text { Light } \\
\text { infection }\end{array}$ & $\begin{array}{l}\text { Moderate } \\
\text { infection }\end{array}$ & $\begin{array}{l}\text { Heavy } \\
\text { infection }\end{array}$ & $\begin{array}{l}\text { All } \\
\text { infections }\end{array}$ \\
\hline Light infection $(1-100)$ & 101 & $71(70.3)$ & 27 & 2 & 1 & 30 \\
\hline Moderate infection $(101-400)$ & 42 & $21(50.0)$ & 18 & 3 & 0 & 21 \\
\hline Heavy infection $(>400)$ & 18 & $6(33.3)$ & 11 & 0 & 1 & 12 \\
\hline All infections $(>0)$ & 161 & $98(60.9)$ & 56 & 5 & 2 & 63 \\
\hline
\end{tabular}


Table 5 Parasitological cure rate after praziquantel treatment in relation to sex and age

\begin{tabular}{lllll}
\hline Indicator & $\begin{array}{l}\text { No. of } \\
\text { patients } \\
\text { infected }\end{array}$ & $\begin{array}{l}\text { No. of } \\
\text { patients } \\
\text { cured (\%) }\end{array}$ & $\chi^{2}$ & $P$-value \\
\hline $\begin{array}{l}\text { Sex } \\
\text { Male }\end{array}$ & 90 & $56(62.2)$ & & \\
Female & 71 & $42(59.2)$ & 0.16 & 0.69 \\
Age & & & & \\
$<10$ & 15 & $12(80.0)$ & & \\
$10-14$ & 27 & $16(59.3)$ & & \\
$15-24$ & 30 & $15(50.0)$ & & \\
$25-39$ & 42 & $23(54.8)$ & & \\
$\geq 40$ & 47 & $32(68.1)$ & 5.51 & 0.24 \\
\hline
\end{tabular}

rates were independent of sex and age categories (Table 5).

As shown in Table 4, most of the moderate and heavy S. mansoni infections were either cleared or reversed to light infections after praziquantel treatment with 4 exceptions. First, 1 heavy infection (mean egg count prior to treatment $3920 \mathrm{epg}$ ) remained heavy, although with a sharp reduction in mean egg counts (928 epg post-treatment). Second, 3 moderate infections remained moderate. Third, there were 2 individuals with light infections pre-treatment who were found with moderate infections post-treatment (mean egg counts changed from 32 and 24 epg pre-treatment to 208 and 304 epg post-treatment, respectively). Fourth, 1 light infection pre-treatment was diagnosed as a heavy infection post-treatment (mean egg counts were 36 and $1008 \mathrm{epg}$ pre- and post-treatment, respectively).

\subsection{Side effects}

Among the 200 treated individuals, 25 (12.5\%) reported 1 or more side effects within $24 \mathrm{~h}$ post-treatment (Table 6). A significantly higher proportion of individuals with high infection intensities reported diarrhoea $\left(\chi^{2}=16.85\right.$, d.f. $=2$, $P<0.001$ ) and dizziness (Fisher's exact test, $P=$ 0.036) when compared to individuals with light or moderate infections. None of the other side effects showed an association with infection intensity, and side effects showed no association with age categories. Abdominal pain was the only reported side effect that was significantly associated with sex (women 9 cases vs. men 3 cases, $\chi^{2}=4.02$, $P=0.045)$.

\section{Discussion}

The parasitological cure rate of $60.9 \%$ following the administration of a single oral dose of $40 \mathrm{mg} / \mathrm{kg}$ praziquantel to $S$. mansoni-infected individuals from western Côte d'Ivoire was at the bottom end of the usually reported cure rates of $60-90 \%$ in different epidemiological settings, using the same antischistosomal drug against this schistosome species (Davis, 1993; Kumar and Gryseels, 1994; Utzinger et al., 2000a). However, markedly lower cure rates of only $18-39 \%$ were observed in a recent and very intense focus of S. mansoni in northern Senegal. After in-depth analysis of these data several explanations were offered to interpret the unexpectedly low cure rates (Danso-Appiah and De Vlas, 2002; Gryseels et al., 2001). In the study presented here the overall egg count reduction was also low $(61.4 \%)$ : this is considerably lower than

Table 6 Number (\%) of reported side effects among those 25 individuals (out of the total of 200 treated individuals) who complained of 1 or more side effects within $24 \mathrm{~h}$ after praziquantel administration in relation to Schistosoma mansoni infection intensity pre-treatment

\begin{tabular}{|c|c|c|c|c|c|c|}
\hline \multirow[t]{2}{*}{ Reported side effects } & \multicolumn{3}{|c|}{ Infection intensity pre-treatment } & \multirow[t]{2}{*}{ Total records } & \multirow[t]{2}{*}{$x^{2}$} & \multirow[t]{2}{*}{$P$-value } \\
\hline & Light $(n=128)$ & Moderate $(n=53)$ & Heavy $(n=19)$ & & & \\
\hline Abdominal pain & $6(4.7)$ & $3(5.7)$ & $3(15.8)$ & 12 & & $0.13^{*}$ \\
\hline Dizziness & $4(3.1)$ & $5(9.4)$ & $3(15.8)$ & 12 & & $0.04^{*}$ \\
\hline Diarrhoea & $4(3.1)$ & 0 & $4(21.1)$ & 8 & 16.85 & $<0.001$ \\
\hline Itching & $2(1.6)$ & $2(3.8)$ & $1(5.3)$ & 5 & & $0.35^{*}$ \\
\hline Vomiting & $1(0.8)$ & 0 & $1(5.3)$ & 2 & 4.09 & 0.13 \\
\hline Headache & $1(0.8)$ & $1(1.9)$ & 0 & 2 & & $0.59^{*}$ \\
\hline Nausea & $1(0.8)$ & $1(1.9)$ & 0 & 2 & & $0.59^{*}$ \\
\hline Urticaria & $1(0.8)$ & 0 & 0 & 1 & 0.57 & 0.75 \\
\hline Total & 20 & 12 & 12 & 44 & & \\
\hline
\end{tabular}

* $P$-value was based on Fisher's exact test. 
the normally reported egg count reductions of over $80 \%$ or $90 \%$ (Gryseels et al., 1987; Utzinger et al., 2000a). It was even lower than in Senegal where 2 different studies revealed egg count reductions of 71\% (Picquet et al., 1998) and 86\% (Stelma et al., 1995). Recent work employing a 2-treatment protocol against S. mansoni in Senegal resulted in a cure rate of $76 \%$ and egg count reduction of $88 \%$ (Picquet et al., 1998). These findings indicated that intense disease transmission is an important factor explaining, at least partially, the apparent lack of praziquantel efficacy in the Senegal focus (Kusel and Hagan, 1999). Other studies drew the same conclusions although they remained short on quantification (for a review see Danso-Appiah and De Vlas, 2002). Pre-patent infections may also account for some of the 'treatment failures', since juvenile stages of S. mansoni are largely insensitive to praziquantel (Sabah et al., 1986; Xiao et al., 1985). The design of the present study did not allow quantification of the extent of pre-patent infections.

Concurrent infections with other parasites and host-related factors have also been found to influence cure rates and egg count reductions. A study in Senegal, investigated different host-related factors between those persons who were cured and those who remained S. mansoni egg-positive despite treatment (van Lieshout et al., 1999). Interestingly, age and pre-treatment infection intensities were the only 2 factors that were significantly associated with low cure rates, while humoral immune responses showed no apparent association. Other studies also demonstrated that cure rates depend on infection intensities prior to praziquantel chemotherapy. These findings are consistent both for S. mansoni and S. haematobium (Andrews, 1981; Berhe et al., 1999; N'Goran et al., 2003; Picquet et al., 1998; Stelma et al., 1995; Utzinger et al., 2000a). Our study adds to this body of evidence, as there was also a highly significant association between $\mathrm{S}$. mansoni infection intensity prior to treatment and cure rates. While heavy infections (>400 epg) showed a low cure rate of only $33.3 \%$, light infections were cleared in $70.3 \%$ of the cases. Comparably low cure rates of $42.9 \%$ among heavy infections (401-1000 epg) were found by Picquet et al. (1998) in Senegal after the initial praziquantel treatment. The overall cure rate in this group increased to $86 \%$ after the second praziquantel treatment. Infections with more than $1000 \mathrm{epg}$ resulted in cure rates of $27 \%$ and $78 \%$ after the first and second round of treatment, respectively. Consequently, administration of 2 doses of praziquantel within a few weeks was proposed for the treatment of heavy infections in this setting. This approach also showed success against S. haemato- bium in a highly endemic area of Côte d'Ivoire with an overall cure rate of $93 \%$ after two praziquantel treatments (N'Goran et al., 2003).

The peak in S. mansoni prevalence was observed in the age group of 15-24 years, which is consistent with previous studies where the overall prevalence and intensity of infection were relatively low (Fulford et al., 1992). The evidence suggests that in populations where the level of infection is high, immunity will be acquired more rapidly, and consequently the peak prevalence will occur at younger age. In contrast, immunity will be acquired later when levels of infections are low and consequently the peak will be expected in older ages (Anderson and May, 1985; Woolhouse, 1998).

In most community-based studies, cure rates have been estimated on the basis of only 1 or 2 Kato-Katz readings, usually derived from single stool specimens (Danso-Appiah and De Vlas, 2002; Gryseels et al., 2001). Our study is based on examination of 3 Kato-Katz thick smears derived from consecutive stool specimens, both prior and after praziquantel administration, to overcome the inherent problem of day-to-day variation in $S$. mansoni egg outputs (Barreto et al., 1990; De Vlas and Gryseels, 1992; De Vlas et al., 1992; Engels et al., 1996; Utzinger et al., 2001). In our previous work carried out in a neighbouring village we showed that examination of at least 3 consecutive Kato-Katz thick smears results in a high diagnostic sensitivity (Utzinger et al., 1998). Examination of multiple stool specimens is of particular relevance after implementation of chemotherapeutic interventions, when the overall geometric mean egg count is likely to be low. The present study reiterates that adherence to such sensitive diagnoses is mandatory for estimation of 'true' cure rates (De Vlas and Gryseels, 1992; Doenhoff, 1998; Utzinger et al., 2000a). The apparent cure rate after examination of single stool specimens before and after praziquantel administration was $87.6 \%$, whereas the 'true' cure rate was only $60.9 \%$. Several authors emphasised the lack of uniform methodologies when assessing praziquantel efficacies and imply the need to standardize treatment and evaluation protocols, so that findings can be readily compared between different settings, facilitating the interpretation of cure rates and in turn elucidating the potential development of resistance to praziquantel (Danso-Appiah and De Vlas, 2002; Geerts and Gryseels, 2000; Utzinger et al., 2001).

Side effects due to praziquantel were mild and transient, i.e. they occurred in the first hours after treatment and gradually resolved within $24 \mathrm{~h}$. They were consistent with those side effects reported in other schistosome-endemic areas. Abdominal 
pain and dizziness were the most prominent side effects, followed by diarrhoea. Among these both diarrhoea and dizziness showed significant associations with pre-treatment infection intensities. Previous studies also found higher frequencies of side effects among the heaviest infection intensities, which had been explained by dying schistosomes and the release of their products. Therefore, severe side effects are mainly encountered in the highest intensity areas (Cioli and Pica-Mattoccia, 2003; Polderman et al., 1984; Stelma et al., 1995).

There is another important aspect of the present study worth discussing. It was carried out among all inhabitants of 75 randomly selected households, thus containing the entire age range. Most previous studies pertaining to the epidemiology of schistosomiasis focused on a particular age group, usually school-age children (Howard et al., 2001). This is explained by the fact that this age group is at highest risk of acquiring the disease, which is primarily driven by behavioural and immunological factors. Consequently, school-age children display high prevalences and intensities of schistosome-infections, and often show lower cure rates than adults (van Lieshout et al., 1999). Therefore, care is needed in the interpretation of cure rates following praziquantel administration because of this potential age bias. To our knowledge this is the first detailed study evaluating praziquantel efficacy against $S$. mansoni in an entire community of Côte d'Ivoire. It complements those 11 studies that were previously carried out in different settings of Africa, and that were included in a recent meta-analysis for interpretation of praziquantel cure rates (Danso-Appiah and De Vlas, 2002). To this end, our work is an important contribution to the ongoing monitoring of praziquantel efficacy against different schistosome species in various endemic areas.

Finally, our findings may raise suspicion about the possible development of praziquantel tolerance or resistance, and this is the subject of current analyses. Although laboratory experiments showed that the degree of praziquantel resistance exhibited by drug-insusceptible isolates is relatively low, and may not be clinically relevant, failure to monitor these developments may have serious consequences in the longer term (Doenhoff et al., 2002). With the launch of new control initiatives that focus on large-scale administration of praziquantel in countries of sub-Saharan Africa (Fenwick et al., 2003), monitoring drug efficacy over time must become an integral part of control programme evaluation in general, and the surveillance of praziquantel resistance development in particular.

\section{Acknowledgements}

We thank all the study participants from Zouatta II for their commitment in the present study. Thanks are addressed to the laboratory technicians, Alphonse Allangba, Abdoulay Fondio, Kouassi L. Lohourignon, Brou Sosthène and Mamadou Traoré, for their excellent work. We thank Oulaï Innocent, Séponh Bernard, Séyouo Anatole, Blé Victor, Poté Kouao Apolinaire, Mahan Mathias, Djinhin Monique, Thes Larissa and Touho Gaston, community health worker from the neighbouring village of Fagnampleu, for the help during the parasitological and household surveys. This investigation received financial support from the Claire Sturzenegger-Jean Favre Foundation. Isaac I. Bogoch thanks the University of Toronto Medical Alumni Association for an International Summer Research Scholarship. Jürg Utzinger is grateful to the Centre for Health and Wellbeing at Princeton University and the Swiss Tropical Institute for financial support.

\section{References}

Anderson, R.M., May, R.M., 1985. Herd immunity to helminth infection and implications for parasite control. Nature 315, 493-496.

Andrews, P., 1981. A summary of the efficacy of praziquantel against schistosomes in animal experiments and notes on its mode of action. Arzneimittelforschung 31, 538-541.

Barreto, M., Smith, D., Sleigh, A., 1990. Implications of faecal egg count variation when using the Kato-Katz method to assess Schistosoma mansoni infections. Trans. R. Soc. Trop. Med. Hyg. 84, 554-555.

Bergquist, N.R., 2002. Schistosomiasis: from risk assessment to control. Trends Parasitol. 18, 309-314.

Berhe, N., Gundersen, S.G., Abebe, F., Birrie, H., Medhin, G., Gemetchu, T., 1999. Praziquantel side effects and efficacy related to Schistosoma mansoni egg loads and morbidity in primary school children in north-east Ethiopia. Acta Trop. $72,53-63$.

Cioli, D., 2000. Praziquantel: is there real resistance and are there alternatives? Curr. Opin. Infect. Dis. 13, 659-663.

Cioli, D., Pica-Mattoccia, L., 2003. Praziquantel. Parasitol. Res. 90(Suppl. 1), 3-9.

Danso-Appiah, A., De Vlas, S.J., 2002. Interpreting low praziquantel cure rates of Schistosoma mansoni infections in Senegal. Trends Parasitol. 18, 125-129.

Davis, A., 1993. Antischistosomal drugs and clinical practice, in Jordan, P., Webbe, G., Sturrock, R.F. (Eds)., Human Schistosomiasis. CAB International, Wallingford, pp. 367-404.

De Vlas, S.J., Gryseels, B., 1992. Underestimation of Schistosoma mansoni prevalences. Parasitol. Today 8, 274-277.

De Vlas, S.J., Van Oortmarssen, G.J., Gryseels, B., 1992. Validation of a model for variations in Schistosoma mansoni egg counts. Trans. R. Soc. Trop. Med. Hyg. 86, 645.

Doenhoff, M.J., 1998. Is schistosomicidal chemotherapy sub-curative? Implications for drug resistance. Parasitol. Today $14,434-435$.

Doenhoff, M.J., Kusel, J.R., Coles, G.C., Cioli, D., 2002. Resistance of Schistosoma mansoni to praziquantel: is there 
a problem? Trans. R. Soc. Trop. Med. Hyg. 96, 465469.

Doumenge, J.P., Mott, K.E., Cheung, C., Villenave, D., Chapuis, O., Perrin, M.F., Reaud-Thomas, G., 1987. Atlas of the Global Distribution of Schistosomiasis. World Health Organization \& Presses Universitaires de Bordeaux (WHO-CEGET-CNRS), Geneva.

Engels, D., Nahimana, S., Gryseels, B., 1996. Comparison of the direct faecal smear and two thick smear techniques for the diagnosis of intestinal parasitic infections. Trans. R. Soc. Trop. Med. Hyg. 90, 523-525.

Fenwick, A., Savioli, L., Engels, D., Bergquist, N.R., Todd, M.H., 2003. Drugs for the control of parasitic diseases: current status and development in schistosomiasis, Trends Parasitol. 19, 509-515.

Fulford, A.J.C., Butterworth, A.E., Sturrock, R.F., Ouma, J.H., 1992. On the use of age-intensity data to detect immunity to parasitic infections, with special reference to Schistosoma mansoni in Kenya. Parasitology 105, 219-227.

Geerts, S., Gryseels, B., 2000. Drug resistance in human helminths: current situation and lessons from livestock. Clin. Microbiol. Rev. 13, 207-222.

Gryseels, B., Nkulikyinka, L., Coosemans, M.H., 1987. Field trials of praziquantel and oxamniquine for the treatment of schistosomiasis mansoni in Burundi. Trans. R. Soc. Trop. Med. Hyg. 81, 641-644.

Gryseels, B., Mbaye, A., De Vlas, S.J., Stelma, F.F., Guissé, F., Van Lieshout, L., Faye, D., Diop, M., Ly, A., Tchuem-Tchuenté, L.A., Engels, D., Polman, K., 2001. Are poor responses to praziquantel for the treatment of Schistosoma mansoni infections in Senegal due to resistance? An overview of the evidence. Trop. Med. Int. Health 6, 864-873.

Howard, S., Donnell, C., Chan, M., 2001. Methods for estimation of associations between multiple species parasite infections. Parasitology 122, 233-251.

Jaoko, W.G., Muchemi, G., Oguya, F.O., 1996. Praziquantel side effects during treatment of Schistosoma mansoni infected pupils in Kibwezi, Kenya. East Afr. Med. J. 73, 499-501.

Katz, N., Chaves, A., Pellegrino, J., 1972. A simple device for quantitative stool thick smear technique in schistosomiasis mansoni. Rev. Inst. Med. Trop. São Paulo 14, 397-400.

Kumar, V., Gryseels, B., 1994. Use of praziquantel against schistosomiasis: a review of current status. Int. J. Antimicrob. Agents 4, 313-320.

Kusel, J., Hagan, P., 1999. Praziquantel - its use, cost and possible development of resistance. Parasitol. Today 15, 352354.

Lemeshow, S., Robinson, D., 1985. Surveys to measure programme coverage and impact: a review of the methodology used by the expanded programme on immunization. World Health Stat. Q. 38, 65-75.

N'Goran, E.K., Gnaka, H.N., Tanner, M., Utzinger, J., 2003. Efficacy and side-effects of two praziquantel treatments against Schistosoma haematobium infection, among schoolchildren from Côte d'Ivoire. Ann. Trop. Med. Parasitol. 97, 37-51.

Picquet, M., Vercruysse, J., Shaw, D.J., Diop, M., Ly, A., 1998. Efficacy of praziquantel against Schistosoma mansoni in northern Senegal. Trans. R. Soc. Trop. Med. Hyg. 92, 90-93.

Polderman, A.M., Gryseels, B., Gerold, J.L., Mpamila, K., Manshande, J.P., 1984. Side effects of praziquantel in the treat- ment of Schistosoma mansoni in Maniema. Zaire. Trans. R. Soc. Trop. Med. Hyg. 78, 752-754.

Renganathan, E., Cioli, D., 1998. An international initiative on praziquantel use. Parasitol. Today 14, 390-391.

Sabah, A.A., Fletcher, C., Webbe, G., Doenhoff, M.J., 1986. Schistosoma mansoni: chemotherapy of infections of different ages. Exp. Parasitol. 61, 294-303.

Savioli, L., Stansfield, S., Bundy, D.A.P., Mitchell, A., Bhatia, R., Engels, D., Montresor, A., Neira, M., Shein, A.M., 2002. Schistosomiasis and soil-transmitted helminth infections: forging control efforts. Trans. R. Soc. Trop. Med. Hyg. 96, 577-579.

Stelma, F., Talla, I., Sow, S., Kongs, A., Niang, M., Polman, K., Deelder, A., Gryseels, B., 1995. Efficacy and side effects of praziquantel in an epidemic focus of Schistosoma mansoni. Am. J. Trop. Med. Hyg. 53, 167-170.

Utzinger, J., N'Goran, E.K., Esse Aya, C.M., Acka Adjoua, C., Lohourignon, K.L., Tanner, M., Lengeler, C., 1998. Schistosoma mansoni, intestinal parasites and perceived morbidity indicators in schoolchildren in a rural endemic area of western Côte d'Ivoire. Trop. Med. Int. Health 3, 711-720.

Utzinger, J., N'Goran, E.K., N’Dri, A., Lengeler, C., Tanner, M., 2000a. Efficacy of praziquantel against Schistosoma mansoni with particular consideration for intensity of infection. Trop. Med. Int. Health 5, 771-778.

Utzinger, J., N'Goran, E.K., Ossey, Y.A., Booth, M., Traoré, M., Lohourignon, K.L., Allangba, A., Ahiba, L.A., Tanner, M., Lengeler, C., 2000b. Rapid screening for Schistosoma mansoni in western Côte d'Ivoire using a simple school questionnaire. Bull. World Health Organ. 78, 389-398.

Utzinger, J., Booth, M., N'Goran, E.K., Müller, I., Tanner, M., Lengeler, C., 2001. Relative contribution of day-to-day and intra-specimen variation in faecal egg counts of Schistosoma mansoni before and after treatment with praziquantel. Parasitology 122, 537-544.

Utzinger, J., Keiser, J., Xiao, S.H., Tanner, M., Singer, B.H., 2003. Combination chemotherapy of schistosomiasis in laboratory studies and clinical trials. Antimicrob. Agents Chemother. 47, 1487-1495.

van Lieshout, L., Stelma, F.F., Guissé, F., Falcao Ferreira, S.T., Polman, K., van Dam, G.J., Diakhate, M., Sow, S., Deelder, A., Gryseels, B., 1999. The contribution of host-related factors to low cure rates of praziquantel for the treatment of Schistosoma mansoni in Senegal. Am. J. Trop. Med. Hyg. 61, 760-765.

Wegner, D.H.G., 1984. The profile of the trematodicidal compound praziquantel. Arzneimittelforschung 34, 11321136.

WHO, 1999. Report of the WHO Informal Consultation on Monitoring of Drug Efficacy in the Control of Schistosomiasis and Intestinal Nematodes. Geneva: World Health Organization, WHO/CDS/CPC/SIP/99.1.

WHO, 2002. Prevention and Control of Schistosomiasis and Soil-Transmitted Helminthiasis: Report of the WHO Expert Committee. Geneva: World Health Organization, Technical Report Series, no. 912.

Woolhouse, M.E.J., 1998. Patterns in parasite epidemiology: the peak shift. Parasitol. Today 14, 428-434.

Xiao, S.H., Catto, B.A., Webster, L.T., 1985. Effects of praziquantel on different developmental stages of Schistosoma mansoni in vitro and in vivo. J. Infect. Dis. 151, 1130-1137.

Available online at www.sciencedirect.com

science@directo 